\title{
The pattern of reflex recovery during spinal shock
}

\author{
H-Y Ko ${ }^{1}$, JF Ditunno Jr*,2, V Graziani ${ }^{2}$ and JW Little ${ }^{3}$ \\ ${ }^{1}$ Department of Rehabilitation Medicine, Pusan National University Hospital, Pusan National University College of \\ Medicine, Pusan, Korea; ${ }^{2}$ Department of Rehabilitation Medicine, Jefferson Medical College of Thomas Jefferson \\ University, Philadelphia, Pennsylvania, USA; ${ }^{3}$ Department of Rehabilitation Medicine, University of Washington, \\ Seattle, Washington, USA
}

\begin{abstract}
Study Design: A prospective descriptive study of the course of recovery of reflexes following acute spinal cord injury (SCI).

Objectives: The purpose of the study was to observe the pattern of reflex recovery following acute SCI in order to determine the prognostic significance of reflexes for ambulation and their relationship to spinal shock.

Setting: A regional spinal cord injury center in Philadelphia, Pennsylvania, USA.

Methods: Fifty subjects admitted consecutively over a 9 month period and on the day of injury were observed for the following reflexes; bulbo-cavernosis (BC), delayed plantar response (DPR), cremasteric (CRM), ankle jerk (AJ), knee jerk (KJ), and normal plantar response for 5-7 days a week and 6-8 weeks duration. The 50 subjects were assessed for ambulation of 200 feet at time of discharge. MRI studies were reviewed on 13/28 complete (ASIA A) injuries.

Results: Thirty-five subjects (28 ASIA A, 4 ASIA B, 3 ASIA C) had a DPR of 2 days or longer duration and these subjects were not ambulatory. The fourteen subjects (12 ASIA D and 2 ASIA C), who were ambulatory, either had no DPR (11/14) or had a DPR of only 1 days duration (3/14). One subject (ASIA B) was not ambulatory and had a DRP of 1 days duration. The DPR was the first reflex to recover most often, followed by the BC, CRM in the first few days and later followed by the deep tendon reflexes (AJ \& $\mathrm{KJ}$ ) by $1-2$ weeks respectively. Less than $8 \%$ of subjects had no reflexes on the day of injury and the reflexes did not follow a caudal-rostral pattern of recovery.

Conclusions: Prognosis for ambulation based on reflexes early after SCI should not be linked to current descriptions of spinal shock. In fact, the view of spinal shock, based on the absence of reflexes and the recovery of reflexes in a caudal to rostral sequence, is of limited clinical utility and should be discarded. The evolution of reflexes over several days following injury may be more relevant to prognosis than the use of the term spinal shock and the presence or absence of reflexes on the day of injury.
\end{abstract}

Keywords: spinal cord injury; deep tendon reflex; plantar reflex; ambulation; outcome; spinal shock

\section{Introduction}

The term spinal shock, although in use since $1850{ }^{1}$ refers to the absence or depression of segmental spinal reflexes that accompany a rostral spinal cord injury. Its cause, however, remains obscure. ${ }^{2,3}$ Based on animal studies, spinal shock is due to loss of normal facilitation and/or inhibition onto cord interneurons and motorneurons from corticospinal, rubrospinal, vestibulospinal and reticulospinal pathway. ${ }^{4-6}$

*Correspondence: JF Ditunno, Jr., MD, Department of Rehabilitation Medicine, Thomas Jefferson University Hospital, 111 S. 11th Street, Suite 375 Main Building, Philadelphia, Pennsylvania 19107, USA
Its utility as a clinical term has been reduced by statements that one can not prognosticate until the patient emerges from spinal shock. ${ }^{7}$ According to Holdsworth, ${ }^{8}$ as segmental reflexes recover (ie as spinal shock resolves) from rostral spinal cord injury, and no accompanying recovery of voluntary movement is observed, then the prognosis for ultimate functional recovery is extremely poor. These reports assume a defined period when spinal shock ceases. As originally described, spinal shock is associated with severe injury or transection of the spinal cord in which there is sensory loss, motor paralysis and a gradual recovery of reflexes following their complete abolition. ${ }^{1,9}$ Does spinal shock's initial phase end, when reflexes begin to recover? Which reflexes does this refer 
to; cutaneous, which are polysynaptic, deep tendon, which are monosynaptic or pathological reflexes, such as the Babinski sign, which is multisegmental?

Although Guttmann ${ }^{10}$ stated that the recovery of reflexes was quite variable in man, he indicated they followed a pattern and the first reflexes to return were the bulbocavernosis (BC) and the anal cutaneous. Although he reported on only five cases, there had been detailed descriptions of reflex recovery by Riddock $^{11}$ and Guillian ${ }^{12}$ from World War I. The clinical findings in these complete injuries were often confirmed by evidence of cord transection at postmortem examination due to the high mortality ${ }^{13}$ at this time. Guttmann ${ }^{10}$ suggested, however, there was a need to study the reflex recovery serially and systematically in order to better understand the pattern of recovery from spinal shock and its prognostic significance. In response to this suggestion and reports by ourselves ${ }^{14}$ and others ${ }^{15}$ of the presence and prognostic significance of a pathological reflex known as the delayed plantar response (DPR), which occurs early after spinal cord injury (SCI), it appeared reasonable to examine more thoroughly reflex recovery during the immediate period following SCI. In addition, due to the increased emphasis on relating initial neurological findings alone to functional recovery ${ }^{16-18}$ or combined with imaging studies ${ }^{19,20}$ electrophysiological studies ${ }^{21,22}$ and histopathology, ${ }^{23,24}$ the following study was undertaken.

The purpose of the study was to observe the pattern of reflex recovery following acute SCI in order to determine the prognostic significance of the reflexes and the relationship to spinal shock. We hypothesized that the presence and duration of the delayed plantar response correlated with the severity of the injury to the spinal cord and the prognosis for ambulation.

\section{Method}

Seventy patients with a diagnosis of acute SCI were admitted during a 9 month period $(4 / 96-1 / 97)$ to a regional SCI center within $24 \mathrm{~h}$ of injury. The majority of patients received methylprednisolone except those sustaining a gunshot wound. Seventeen patients with SCI and associated lower extremity fracture, preexisting neurological deficit or lower motor neuron injury or disease were excluded. Of the remaining 53 patients the mechanisms of injury included motor vehicle accidents $(n=17)$, falls $(n=17)$, violence including gun shot wounds $(n=15)$ and sports $(n=4)$. Neurological testing, both motor and sensory, was performed on each subject, according to the International Standards for Neurological and Functional Classification of Spinal Cord Injury, ${ }^{25}$ to determine the neurological level of injury and ASIA Impairment Scale. The following reflexes were recorded in the emergency room and 5 of 7 days serially for $6-8$ weeks by one of the authors (H-Y Ko); bulbocavernosis, delayed plantar, cremasteric, Babinski, ankle jerk, knee jerk and normal plantar. These examinations were performed in the acute spinal cord unit following admission from the emergency room and continued after transfer to the rehabilitation unit in 2-3 weeks. The ASIA impairment grade was determined at the time of the initial neurological examination in the emergency room.

The normal plantar response and the Babinski sign were elicited by a lightly applied stimulus to the lateral sole of the foot in the area of the S1 dermatome. Flexion of the toes (normal plantar response) and extension of the toes (Babinski sign) are brisk reactions and the response to stimuli are less than $90 \mathrm{~ms}^{26}$ The delayed plantar response, however requires an unusually strong stimulus, in contrast to the Babinski sign or normal plantar response, and is applied by stroking with a blunt instrument upward from the heel toward the toes along the lateral sole of the foot continued medially across the volar aspect of the metatarsal heads. Following the stimulus the toes flex and relax in a delayed sequence, which at times is robust and at other times is slight. ${ }^{14}$ The duration of the stimulus to the foot and the response of the flexor digitorum brevis muscle was recorded in a representative patient. The sole of the foot was stimulated mechanically by a sharp object picked up by a surface electrode. The EMG tracing was recorded from a needle electrode placed in the flexor digitorum muscles. The recordings were from dual channels and superimposed one on the other (Figure 6).

MRI studies were performed on 13 of the 28 patients with complete injuries, but 10 of 28 subjects were not studied because of a gunshot wound. The remaining five subjects did not have studies due to invasive metal, which precluded a MRI study. The neuroradiologist, who interpreted the MRI studies was blinded to the clinical features of the subjects.

Outcome data for ambulation was determined at time of discharge from the rehabilitation facility. Functional ambulators were defined as a person who were able to walk at least 200 feet with or without orthoses or walking aids at the time of rehabilitation discharge.

Table 1 Onset of reflexes within 2-3 days of injury in subjects with complete injuries (ASIA A) compared to subjects with incomplete injuries (ASIA B \& C and ASIA D). The Fisher Exact Test was calculated to determine significance $(P<0.05)$

\begin{tabular}{lcccrrr}
\hline & $D P R$ & $B C$ & $C R M$ & $B S$ & $A J$ & $K J$ \\
\hline $\begin{array}{l}\text { ASIA A } \\
\quad(n=31)\end{array}$ & 31 & 26 & 11 & 2 & 5 & 2 \\
$\begin{array}{l}\text { ASIA B \& C } \\
\quad(n=10)\end{array}$ & 8 & 10 & 5 & 4 & 8 & 7 \\
$\begin{array}{l}\text { ASIA D } \\
\quad(n=12)\end{array}$ & 1 & 12 & 9 & 10 & 12 & 12 \\
$\begin{array}{l}\text { Total N } \\
P \text { value }\end{array}$ & 53 & 53 & 43 & 53 & 53 & 53 \\
\hline
\end{tabular}


Data on the comparison of patients with complete and incomplete injuries (Table 1) were analyzed by Fisher's Exact Tests. This analysis was used because of the number of cells containing low frequencies. Data on the pattern of recovery by age of subjects (Table 2) were analyzed by Wilcoxon Signed Rank Tests. This analysis was a conservative measure, because of the small number of data points, which may not have been normally distributed.

\section{Results}

Fifty-three of the 70 subjects examined during the first 2 days following injury had clinical evidence of an upper motor neuron injury manifested by the presence of reflexes such as the DPR, BC and/or CRM in complete injuries and additional reflexes in incomplete injuries. Three of these subjects (all ASIA A) died within 14-28 days but were included in the analysis of the initial 2 week recovery period. The remaining 50 subjects, whose mean age was 37.5 years (median age 43 years), were followed to the time of discharge.

Twenty-eight subjects had complete injuries (ASIA A) and remained complete during the period of their follow-up examinations. Twenty-two subjects had incomplete injuries (ASIA B $n=5$, ASIA C $n=5$, ASIA D $n=12$ ) and they remained incomplete during the period of follow-up. Forty-two subjects had cervical injuries $($ Complete $=22$, Incomplete $=20)$ and 11 subjects had thoracic injuries (Complete $=9$, Incomplete $=2$ ). The three subjects, who died, had cervical injuries.

\section{Reflex changes after complete SCI}

The DPR was present in all subjects with complete injuries $(31 / 31)$. It was the first reflex observed in the emergency room (ER) in $11 / 31$ subjects, who had complete injuries (ASIA A), but it followed the BC by $1-2$ days in $4 / 31$ and occurred at the same time as BC in 16 subjects. The DPR, once present, persisted for an average duration of 14.3 days in subjects with complete injuries.

The Babinski sign never occured before the DPR and usually started at some time after the DPR ceased, although, in several subjects it occurred simultaneously for a period of time until the DPR stopped. The cessation of the DPR, therefore, showed an inverse relationship to the beginning of the Babinski sign (see Figure 1). In several subjects in which the stimulus was applied to the sole of the foot and was unusually strong in order to elicit the DPR, there was an immediate dorsiflexion of the great toe (Babinski sign) followed by the DPR suggesting that the same area of stimulation elicited two different reflexes temporarily distinct from each other. This was observed in subjects with complete injuries.

The cremasteric reflex (L1-2) occurred in 11/27 males within 1 day, $17 / 27$ within 3 days, 22/27 within 2 weeks in patients with complete injuries $(1 / 28$ subjects was female). The pattern of recovery of the other initial cutaneous reflexes (BC and DPR) in complete subjects is illustrated in Figure 2.

The ankle jerks (AJ) occurred in 10/28 and the knee jerks (KJ) in $7 / 28$ complete injuries (ASIA A) by the third day following injury (see Figure 3 ). The onset of the deep tendon reflexes ( $\mathrm{AJ}$ and $\mathrm{KJ}$ ) was delayed in complete injuries and the average onset of the AJ was 7.7 days and for the KJ 15.2 days following the injury.

\section{DPR vs Babinski Sign (Complete Injury)}

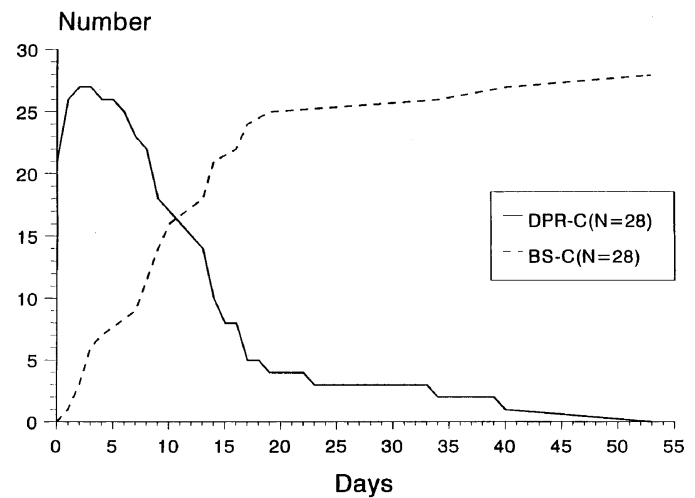

Figure 1 Recovery of the Delayed Plantar Response (DPRC) versus the recovery of the Babinski Sign (BS-C) in 28 complete injuries (ASIA A)

Table 2 Onset of the Ankle Jerk (AJ), Babinski Sign (BS) and the duration of the Delayed Plantar Response (DPR) in 28 subjects with complete injuries (ASIA A) are compared based on the age of two groups. Group $1(n=9)$ are the older subjects (48 years median) and are compared to Group II $(n=19)$, the younger subjects ( 28 years median). Significance was calculated by the Wilcoxon Signed Rank Test

\begin{tabular}{cllll}
\hline & Age & Onset AJ & Onset BS & Duration DPR \\
\hline Group I & 48 years median & 1 days median & 7 days median & 6 days median \\
$n=9$ & 49 years mean & 1.5 days mean & 10 days mean & 11 days mean \\
Group II & 28 years median & 14 days median & 13 days median & 15 days median \\
$n=19$ & 33 years mean & 14 days mean & 14 days mean & 15 days mean \\
& $P<0.05$ & $P<0.001$ & $P<0.01$ & $P<0.05$ \\
\hline
\end{tabular}


Within the 28 complete subjects, two patterns of recovery occurred based on the onset of the AJ, BS, duration of the DPR and the age of the patients (see Table 2). In Group I $(n=9)$, the median age 48 years, the onset of the AJ was one day (median) as compared to Group II, median age 28 years, the onset of the AJ was 13 days (median).

Reflex changes in complete versus incomplete SCI

The DPR was observed in all subjects with complete injuries, but it was present in less than one half of subjects with incomplete injuries (9/22) and these subjects included 5/5 ASIA B, 3/5 ASIA C and 1/12 ASIA D. It was not present in 13 subjects with

\section{Cutaneous Reflexes in Complete}

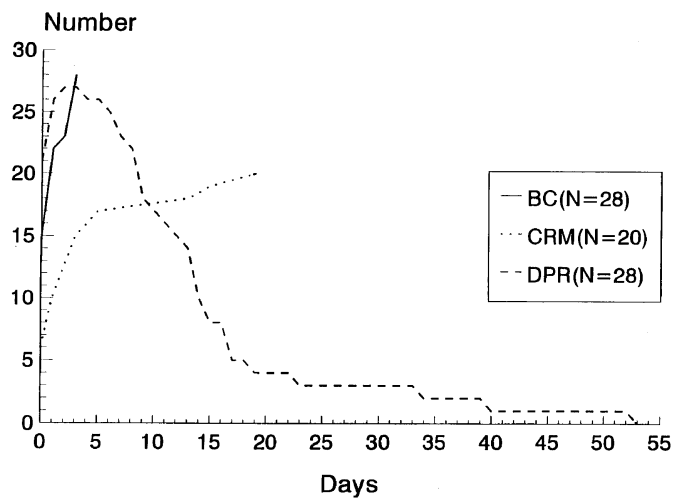

Figure 2 Recovery of the cutaneous reflexes, which includes the Bulbo-cavernosis (BC), the Delayed Plantar Response (DPR) in 28 complete injuries and the Cremasteric (CRM) in 20 male complete injuries (ASIA A)

\section{$\mathrm{BS}, \mathrm{AJ}$, and $\mathrm{KJ}$ in Complete}

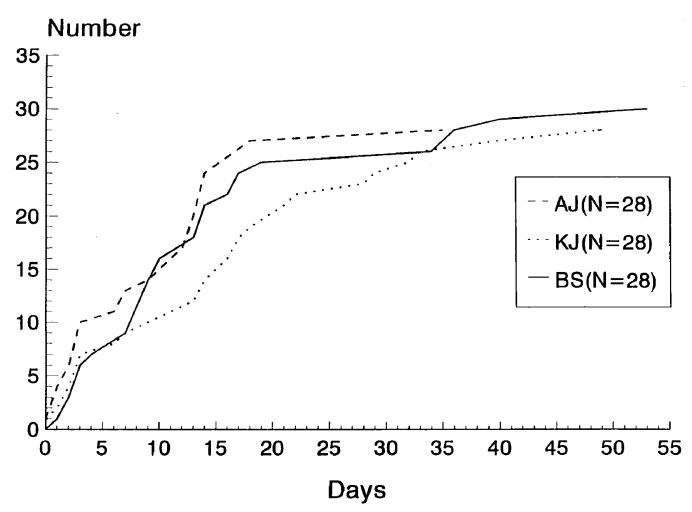

Figure 3 Recovery of the deep tendon reflexes (Ankle JerkAJ, Knee Jerk $-\mathrm{KJ}$ ) and the Babinski Sign in 28 complete injuries (ASIA A) incomplete injuries (ASIA C $n=2$, ASIA D $n=11$ ). The duration of the DPR was 2 days median and 3.8 days mean in subjects with incomplete injuries. In only one case with an incomplete injury the DPR persisted beyond 7 days, whereas the DPR lasted a week or longer in the majority of subjects with a complete injury (ASIA A's 24/31). The Babinski sign appeared within 10 days in all nine patients with incomplete injuries, who had a DPR, but followed no reciprocal pattern as seen in complete injuries. In the subjects with complete injuries only one half had Babinski signs by 10 days and one half still had a DPR present (Figure 1). The Babinski sign in the incomplete subjects recovered significantly earlier than in the complete subjects (Figure 4 and Table $1)$.

The cutaneous reflexes including the $\mathrm{BC}$ and the cremasteric in 8/11 males, together with the deep tendon reflexes were all present in the emergency room in all eleven ASIA D subjects. Deep tendon reflexes were seen in 5/5 ASIA $C$ subjects in the ER, but all five ASIA B subjects had a delay of several days or more of onset of DTR's. The Babinski sign lagged slightly behind the $\mathrm{AJ}$ and $\mathrm{KJ}$ in the incomplete subjects (Figure 5) but all recovered significantly earlier than in the complete injuries (Figure 2 and Table 1).

\section{MRI and ambulation outcome}

MRI studies were performed on less than one half of the subjects $(13 / 28)$ with complete injuries, because of the large number of gunshot wounds or invasive metal present. Little of statistical significance was possible with such limited numbers, related to prognosis of motor recovery and ambulation based on the severity of SCI found on MRI. The only trend of early reflex recovery occurred in subjects with evidence of

\section{Babinski Sign (Complete vs Incomplete)}

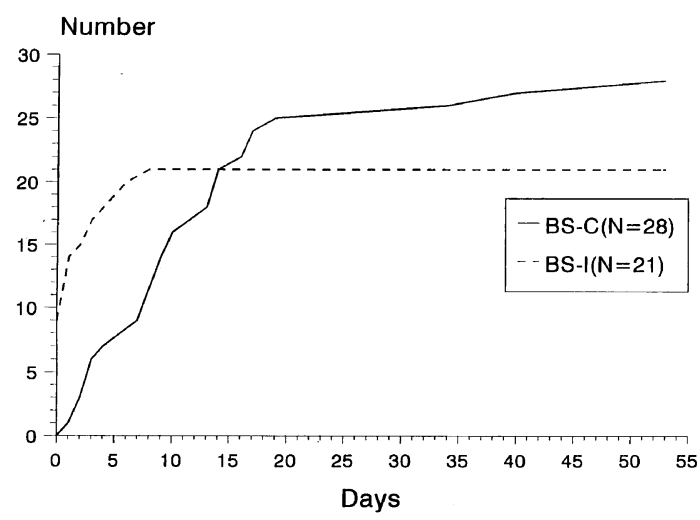

Figure 4 Recovery of the Babinski Sign (BS) in 28 complete injuries (ASIA A) versus 21 incomplete injuries (ASIA B, C and D) 
$\mathrm{BS}, \mathrm{AJ}$, and $\mathrm{KJ}$ in Incomplete

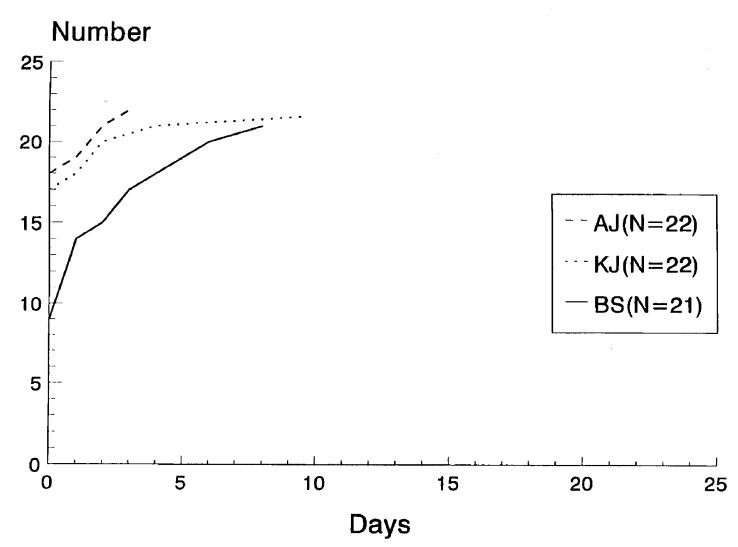

Figure 5 Recovery of the deep tendon reflexes (Ankle Jerk AJ, Knee Jerk - KJ) in 22 incomplete injuries and Babinski Sign (BS) in incomplete injuries (ASIA B, C and D)

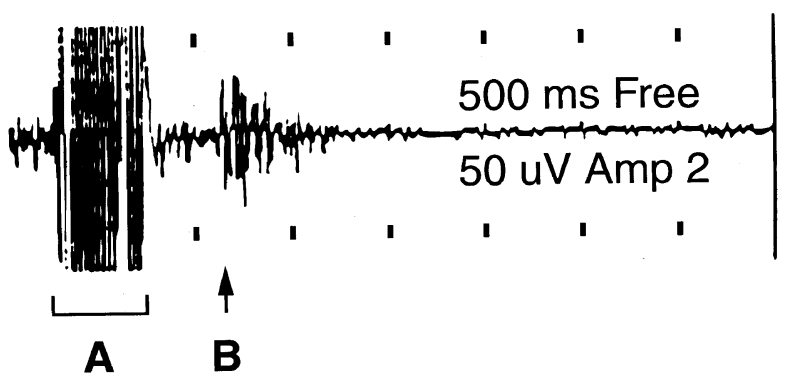

Figure 6 Latency of the Delayed Plantar response. A represents duration of plantar stimulation (duration $500 \mathrm{~ms}$ ) and $\mathbf{B}$ represents initiation of EMG response of flexor digitorum brevis ( $500 \mathrm{~ms}$ post stimulation)

persistent compression of the spinal cord by MRI. In eight subjects with evidence of cord compression the AJ reflex recovered in 6.6 days as compared to the remaining 5/13 in which the $\mathrm{AJ}$ reflex recovered in 12.1 days. There did not appear to be a significant correlation of the presence of cord stenosis or spondylosis and early return of reflexes.

Thirteen (13/50) subjects were ambulatory at the time of discharge from the rehabilitation facility. Two of these subjects (ASIA C $n=1$, ASIA D $n=1$ ), had a DPR of 1 days duration. Of the remaining 37 subjects, who were not ambulatory at the time of discharge, all but one subject had a DPR of 2 days or longer. This included all ASIA A $n=28$, all ASIA B $n=5$ and $3 / 5$ ASIC C. The one subject, who did not ambulate and had a DPR of only 1 days duration was ASIA B on admission and ASIA $\mathrm{C}$ at discharge.

The DPR has been previously described as having a delayed response to an unusually strong stimulus to the sole of the foot and this is illustrated in Figure 6.
In this figure, the duration of the stimulus is $500 \mathrm{~ms}$ and the onset of the response of the flexor digitorum brevis following the stimulus is $500 \mathrm{~ms}$ or a full second following the initiation of the stimulus.

\section{Discussion}

The pattern of reflex recovery after traumatic SCI differs for those with complete SCI (ASIA A) from those with incomplete SCI (ASIA B, C \& D). The most distinguishing reflex was the DPR; it was more often present and lasted longer in those without recovery of voluntary movement. Thus, the continued presence of the DPR has poor prognostic significance for neurological recovery. ${ }^{14,15,27}$ These prognostic findings are consistent with a previous publication ${ }^{14}$ from our center in which the DPR was not performed serially but only at the time of admission and it was not compared to other reflexes. This study, in contrast to our previous report, shows that the DPR occurs more frequently in patients with complete and incomplete injuries, when they are examined serially rather than only at the time of admission. The study also revealed that the duration of the DPR is of greater significance for prognosis of ambulation than its mere presence or absence at the time of admission.

The DPR is a most unusual reflex; its presence and duration correlates with the severity of upper motorneuron damage. It is apparently unmasked for a period of time then disappears, even in complete SCI, as other hyperreflexia develops (eg Babinski sign, tendon hyperreflexia, flexor withdrawal hyperreflexia). It shows a reciprocal relationship with the Babinski sign (Figure 1) and the DPR is gradually replaced by the Babinski sign as observed by Riddock ${ }^{11}$ and Landau $^{26}$ in most patients. Several patients for a short time manifested a Babinski sign followed by a DPR in response to the same area of stimulation. It would appear that the same local signature of stimulation of the S1 dermatome, applied strongly, produces dorsiflexion of the great toe immediately and is then followed by the delayed plantar flexion of the toes, suggesting separate pathways and responses from the same area of stimulation. Van Gijn ${ }^{28}$ in a review of the pathophysiology of the Babinski sign, makes a distinction between the differences in the receptive fields to produce the normal plantar response and the Babinski sign and also refers to the paradoxical downward toe response (DPR). He states 'the normal plantar response is a skin reflex in the strict sense, a unisegmental reflex with a limited receptive field, ... analogous to the abdominal and cremasteric reflexes. The receptive zone for reflex withdrawal of the leg, including dorsiflexion of the hallux, extends beyond the sole of the foot ... and the Babinski toe phenomena is part of the primitive but complex medullary automatism, whereas the normal, downward response of the toes constitutes a separate reflex with a limited receptive field.' Although he refers to the DPR as 'an initial downward response of the toes 
after a cord injury' he does not offer an explanation for the 'long latency and duration'. The physiological basis of the DPR is unclear given its markedly prolonged latency of $500-1000 \mathrm{~ms}$ (see Figure 6). It is likely that considerable temporal summation of afferent input is required and the afferent conduction may be due to very slowly conducting afferents (eg unmyelinated C-fibers). ${ }^{26}$ Because it is only transiently present for days to several weeks after SCI, it has been only minimally studied clinically and neurophysiologically. ${ }^{26}$

Few complete SCI patients (ASIA A within $24 \mathrm{~h}$ at injury and at discharge from rehabilitation) had no reflexes on initial examination ( 2 of 28 subjects) and the majority had two or more reflexes (the DPR and/ or BC and cremasteric reflexes). The deep tendon reflexes were absent in all but one of the complete injuries. The presence of spinal shock, defined as the absence of all reflexes on the day of injury, is unusual in current clinical practice. In fact, almost a third of subjects were examined within $1-3 \mathrm{~h}$ of injury and all had reflexes present. Thus, even though some subjects had high blood alcohol levels, some may have had residual ephaptic effects ${ }^{29}$ given they were within hours of cord injury, some were hypotensive, a few had associated head injury, most were receiving narcotic pain medication, and most were receiving methylprednisolone, some spinal reflexes were elicitable in $93 \%$ of all subjects.

Although some ${ }^{10}$ say after complete SCI, the BC reflex recovers first, followed by the deep tendon reflexes in a caudal to rostral direction; we were unable to confirm this by our observations. The DPR (S1-2) was the first reflex observed in 20 subjects, the $\mathrm{BC}(\mathrm{S} 2-5)$ in 16 and the cremasteric (L2) was seen in five subjects in the emergency room. In only one subject were the $\mathrm{AJ}$ and $\mathrm{KJ}$ present and the average recovery of these reflexes was 7.7 and 15.2 days respectively. In our study, the first elicitable reflexes were the cutaneous, polysynaptic reflexes (DPR, BC, cremasteric) rather than the monosynaptic tendon reflexes and this distinction was more apparent than a caudal-to-rostral distinction. It appears that the cutaneous, polysynaptic reflexes receive less supraspinal facilitation and/or recover faster than the monosynaptic deep tendon reflexes or synaptic zones are less disrupted because descending pathways make less total contribution. ${ }^{30}$

In view of the above, it is difficult to support the proposition that one cannot prognosticate during spinal shock, when spinal shock is defined as the absence of all reflexes. Since all reflexes are rarely absent, we should discard this view of spinal shock. We should also discard the view of spinal shock that reflex return occurs in a caudal to rostral sequence, since the cutaneous reflexes do not follow this rule. Furthermore, the BC reflex is not typically the first reflex to recover in patients with complete injuries. Presence or absence of the BC reflex may aid in distinguishing between upper or lower motoneuron involvement at a segmental level, but it may require several days of observation before this is evident. The immediate presence of the DPR, likewise should be tested for several days following the injury. A more accurate description of spinal shock should characterize this state as a period of altered appearance of cutaneous and deep tendon reflexes and the emergence and at times disappearance of pathologic reflexes over days and weeks. The evolution of spinal reflexes over several days, therefore, appears to be more relevant to the prognosis for ambulation than the mere presence or absence of reflexes on the day of injury.

Another observation of reflex recovery in complete SCI was the presence of $\mathrm{AJ}$ and $\mathrm{KJ}$ in one-third of patients with complete injuries within the first 3-6 days as compared to an average recovery of $1-2$ weeks respectively for the entire 29 subjects. The older age of those that recovered DTRs by 3-6 days suggests that spinal stenosis with preexisting subclinical myelopathy such as the solid cord syndrome ${ }^{31}$ may have contributed to faster recovery of reflexes. The limited number of MRI studies, however, did not confirm the correlation of cervical spondylosis with the early recovery of deep tendon reflexes. Animal studies have clearly shown faster recovery of tendon reflexes in those with prior upper motoneuron lesions (eg motor cortex, vestibular nucleus or cord hemisection, ${ }^{32}$ and absence of spinal shock is well known in patients with slowly progressive myelopathy. ${ }^{11}$ Older patients, who sustain incomplete SCI, have a different clinical course and the majority do not ambulate as compared to a younger group of which $90 \%$ are ambulatory. ${ }^{33}$ This difference in clinical course may also be due to pre-existing damage to the cord in the older subjects, but the MRI studies were inconclusive.

Further study is needed to determine the relative value of the known prognostic signs such as sacral sparing of pinprick, ${ }^{16,34}$ return of voluntary movement by $72 \mathrm{~h},{ }^{35}$ return of spinal reflexes in the absence of recovering voluntary movement ${ }^{10}$ and a DPR, in establishing the prognosis for functional recovery at the earliest possible date. An accurate prediction of recovery is essential to target medications and therapies appropriately toward ambulation or toward wheelchair use, as well as to advise patient and family. Preliminary observations in animals and humans suggest that there may be a critical period during acute rehabilitation when CNS stimulants ${ }^{36}$ aggressive active exercise, ${ }^{37}$ electrical stimulation ${ }^{38}$ and training, such as body weight support ${ }^{39-43}$ can enhance recovery of voluntary movement. As these new rehabilitation interventions develop, failure by rehabilitation physicians to recognize these favorable prognostic signs and failure to initiate these new therapies may result in suboptimal functional outcomes. Current studies of prognosis should be undertaken to incorporate new factors such as the DPR and the severity of the damage to the spinal cord by MRI studies. ${ }^{19}$ These findings could be used ${ }^{20}$ to develop formulas that integrate all of the prognostic 
factors and take into account the new acute interventions such as improved emergency medical technician (EMT) services and neuroprotective agents. ${ }^{4-46}$

The DPR has prognostic significance, when it persists for $48 \mathrm{~h}$ or longer in regard to the severity of the injury (ASIA grade) and the potential for ambulation at the time of discharge. The absence of all reflexes was observed in less than $8 \%$ of cases on the day of injury and it was usually two or more cutaneous reflexes that were present. These cutaneous reflexes are less depressed than the deep tendon reflexes. The cremasteric reflex (L2) often precedes the AJ (L5, S1) and the DPR (S1) frequently precedes the BC (S3-5), which is not consistent with a caudalrostral recovery pattern of reflexes. The DPR, which often precedes or is seen at the same time as the $\mathrm{BC}$, gradually disappears and is followed by the Babinski and shortly thereafter by the $\mathrm{AJ}$ and $\mathrm{KJ}$.

These findings warrant a reconsideration of the term spinal shock, and assumptions based on previous descriptions and a limited examination of reflexes. The evolution of spinal reflexes over several days appears to be more relevant to prognosis for ambulation than the presence or absence of reflexes on the day of injury.

\section{References}

1 Hall M. Synopsis of the diastaltic nervous system: or the system of the spinal marrow, and its reflex arcs; as the nervous agent in all the functions of ingestion and of egestion in the animal oeconomy. London: Mallett J., 1850;

2 Denny-Brown D. Motor mechanisms. In: Field J (ed). Handbook of physiology, section 1. Neurophysiology, part II. American Physiological Society: Washington, DC 1960, pp 781-796.

3 Illis LS. Clinical evaluation and pathophysiology of the spinal cord in the chronic phase. In: Illis LS (ed). Spinal Cord Dysfunction. Oxford University Press: New York 1988; p107128.

4 Barnes CD, Schadt JC. Release of function in the spinal cord. Prog Neurobiol 1979; 12: $1-13$.

5 Mendell LM. Physiological aspects of synaptic plasticity: the Ia/ motoneuron connection as a model. Adv Neurol 1988; 47: $337-$ 360.

6 Leis AA et al. Spinal motoneuron excitability after acute spinal cord injury in humans. Neurology 1966; 47: 231-237.

7 Stauffer ES. Rehabilitation of posttraumatic cervical spinal cord quadriplegia and pentaplegia. In: Cervical Spine Research Society ES (ed). The cervical spine. Lippincott: Philadelphia; 1983; p317-322.

8 Holdsworth F. Fractures, dislocations, and fracture-dislocations of the spine. J Bone Joint Surg Am 1970; 52: 1534-1551.

9 Sherrington CS. The integrative action of the nervous system. Constable: London, 1906;

10 Guttmann L. Studies on reflex activity of the isolated cord in spinal man. J Nerv Ment Dis 1952; 116: 957-972.

11 Riddock $\mathrm{G}$. The reflex functions of the completely divided spinal cord in man, compared with those associated with less severe lesions. Brain 1917; 40: $264-401$.

12 Guillain G, Barre JA. Etude anatomo-clinique de quinze cas de section totalle de la moelle. Annales de Medicine 1917; 4: 178 222.
13 Cushing H. Organization and activities of the neurological service American expeditionary forces. In: Ireland MW, ed. The medical department of the United States Army in the world war. Government Printing Office: Washington, DC, 1927; pp $749-$ 758.

14 Weinstein DE, Ko HY, Graziani V, Ditunno Jr JF. Prognostic significance of the delayed plantar reflex following spinal cord injury. Spinal Cord Med 1997; 20: 207-211.

15 Braakman R, Penning L. Injuries to the cervical spine. In: Vinken PJ, Bruyn GW (eds). Handbook of clinical neurology. NorthHolland: Amsterdam 1976; $227-380$.

16 Crozier KS, Graziani V, Ditunno Jr JF, Herbison GJ. Spinal cord injury: prognosis for ambulation based on sensory examination in patients who are initially motor complete. Arch Phys Med Rehabil 1991; 72: 119-121.

17 Ditunno Jr JF, Stover SL, Freed MM, Ahn JH. Motor recovery of the upper extremities in traumatic quadriplegia: a multicenter study. Arch Phys Med Rehabil 1992; 73: 431-436.

18 Burns SP et al. Recovery of ambulation in motor-incomplete tetraplegia. Arch Phys Med Rehabil 1997; 78: 1169-1172.

19 Flanders AE et al. Acute cervical spine trauma: correlation of MR imaging findings with degree of neurologic deficit. Radiology 1990; 177: $25-33$.

20 Flanders AE et al. Forecasting motor recovery after cervical spinal cord injury: value of MR imaging. Radiology 1996; 201: $649-655$.

21 Dimitrijevic MR, Nathan PW. Studies of spasticicy in man. 3. Analysis of reflex activity evoked by noxious cutaneous stimuli. Brain 1968; 91: 349-368.

22 Calancie B et al. Evidence that alterations in presynaptic inhibition contribute to segmental hypo- and hyperexcitability after spinal cord injury in man. Electroencephalogr Clin Neurophysiol 1993; 89: $177-186$.

23 Croul SE, Flanders AE. Neuropathology of human spinal cord injury. Adv Neurol 1997; 72: 317-323.

24 Bunge RP, Puckett WR, Hiester ED. Observations on the pathology of several types of human spinal cord injury, with emphasis on the astrocyte response to penetrating injuries. $A d v$ Neurol 1997; 72: 305-315.

25 Ditunno Jr JF, Young W, Donovan WH, Creasey G. The international standards booklet for neurological and functional classification of spinal cord injury. American Spinal Injury Association. Paraplegia 1994; 32: 70-80.

26 Landau WM, Clare MH. The plantar reflex in man, with special reference to some conditions where the extensor response is unexpectedly absent. Brain 1959; 82: $321-355$.

27 Anonymous. The sign of Babinski. Lancet 1960; $321-322$.

28 van Gijn J. Pathophysiology. In: The Babinski sign - a centenary. University Utrecht: Uttrecht 1996, pp 89-117.

29 Cavallari P, Pettersson LG. Tonic suppression of reflex transmission in low spinal cats. Exp Brain Res 1989; 77: $201-212$.

30 Illis LS. The motor neuron surface and spinal shock. Mod Trends Neurol 1967; 4: 53-68.

31 Bunge RP, Puckett WR, Becerra JL. Observations on the pathology of human spinal cord injury: A review and classification of 22 new cases with details from a case of chronic cord compression with extensive focal demyelination. In: Seil FJ (ed). Advances in Neurology. Raven Press Ltd: New York 1993, pp $75-89$.

32 Liu C, Chambers W. Interspinal sprouting of dorsal root axons. Arch Neurol 1958; 79: 46-61.

33 Penrod LE, Hegde SK, Ditunno Jr JF. Age effect on prognosis for functional recovery in acute, traumatic central cord syndrome. Arch Phys Med Rehabil 1990; 71: $963-968$.

34 Folman Y, el Masri W. Spinal cord injury: prognostic indicators. Injury 1989; 20: $92-93$.

35 Brown PJ, Marino RJ, Herbison GJ, Ditunno Jr JF. The 72-hour examination as a predictor of recovery in motor complete quadriplegia. Arch Phys Med Rehabil 1991; 72: 546-548. 
36 Walker-Batson D et al. Amphetamine paired with physical therapy accelerates motor recovery after stroke. Further evidence. Stroke 1995; 26: $2254-2259$.

37 Little JW, Harris RM, Lerner SJ. Immobilization impairs recovery after spinal cord injury. Arch Phys Med Rehabil 1991; 72: $408-412$.

38 Muir GD, Steeves JD. Sensorimotor stimulation to improve locomotor recovery after spinal cord injury. Trends Neurosci 1997; 20: $72-77$.

39 Barbeau H, Danakas M, Arsenault B. The effects of locomotor training in spinal cord injured subjects: a preliminary study. Restorative Neurology and Neuroscience 1994; p81-84.

40 Fung J, Stewart JE, Barbeau H. The combined effects of clonidine and cyproheptadine with interactive training on the modulation of locomotion in spinal cord injured subjects. $J$ Neurol Sci 1990; 100: 85-93.

41 Curt A, Keck ME, Dietz V. Clinical value of F-wave recordings in traumatic cervical spinal cord injury. Electroencephalogr Clin Neurophysiol 1997; 105: 189-193.
42 Edgerton VR et al. A physiological basis for the development of rehabilitative strategies for spinally injured patients. $J \mathrm{Am}$ Paraplegia Soc 1991; 14: 150- 157.

43 Wernig A, Muller S. Laufband locomotion with body weight support improved walking in persons with severe spinal cord injuries. Paraplegia 1992; 30: 229-238

44 Bracken MB et al. A Randomized, Controlled Trial of Methylprednisolone or Naloxone in the Treatment of Acute Spinal Cord Injury. New Eng J Med 1990; 322: 1405-1411.

45 Bracken MB et al. Administration of methylprednisolone for 24 or 48 hours or tirilazad mesylate for 48 hours in the treatment of acute spinal cord injury. Results of the Third National Acute Spinal Cord Injury Randomized Controlled Trial. National Acute Spinal Cord Injury Study. JAMA 1997; 277: 1597-1604.

46 Geisler FH, Dorsey FC, Coleman WP. Recovery of motor function after spinal-cord injury - a randomized, placebocontrolled trial with GM-1 ganglioside. New Eng J Med 1991; 324: $1829-1838$. 